Faculty and postdoc., Energy and Environment

\title{
Effect of UV/ozone treatment on surface hydrophilicity and humidity sensing properties of PVDF- BaTiO3 composite films
}

\section{Jibril Al-Metairi, Ruba Ali, Shoaib Mallick, Zubair Ahmed, Noora Al-Thani}
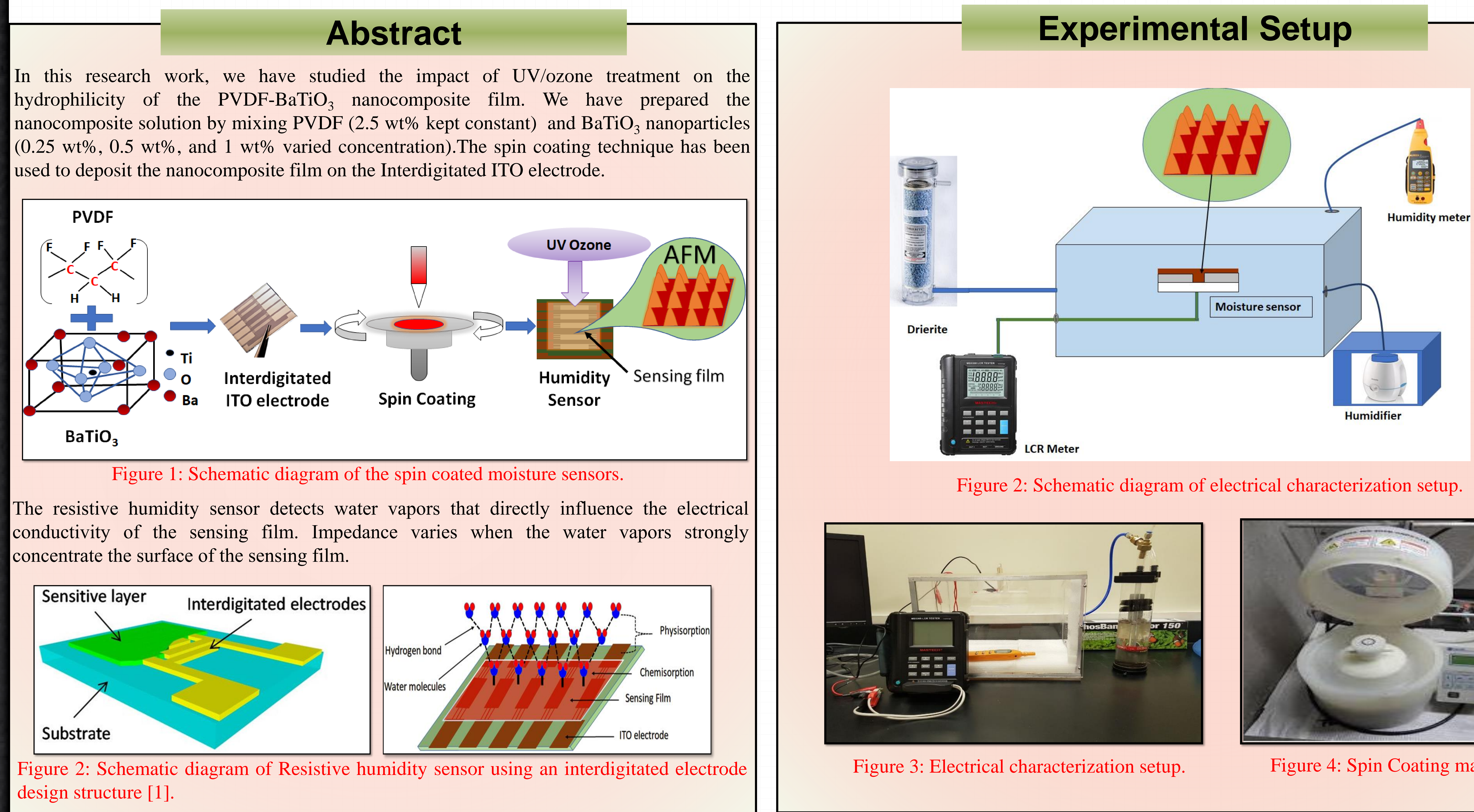

Figure 2: Schematic diagram of electrical characterization setup

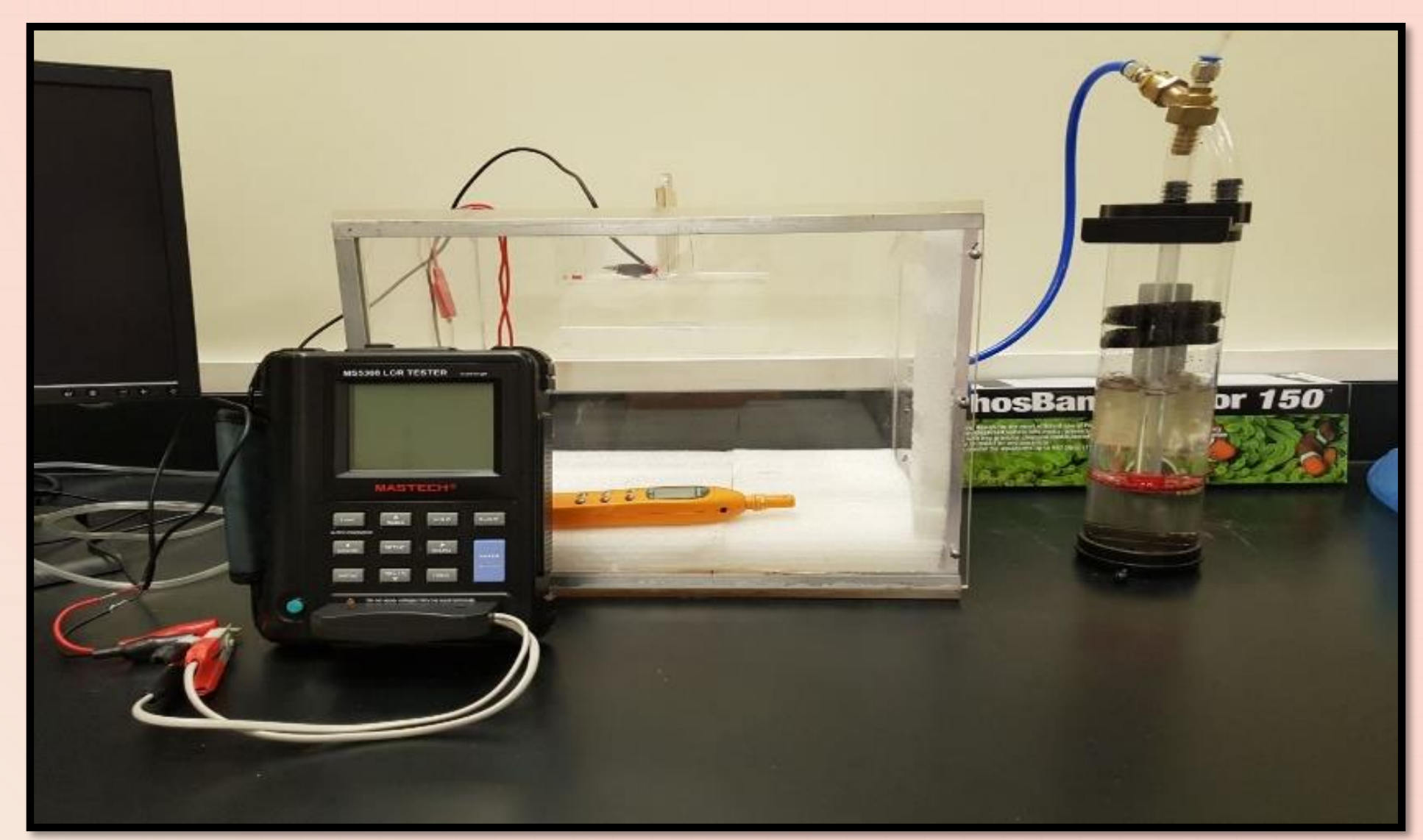

Figure 3: Electrical characterization setup.

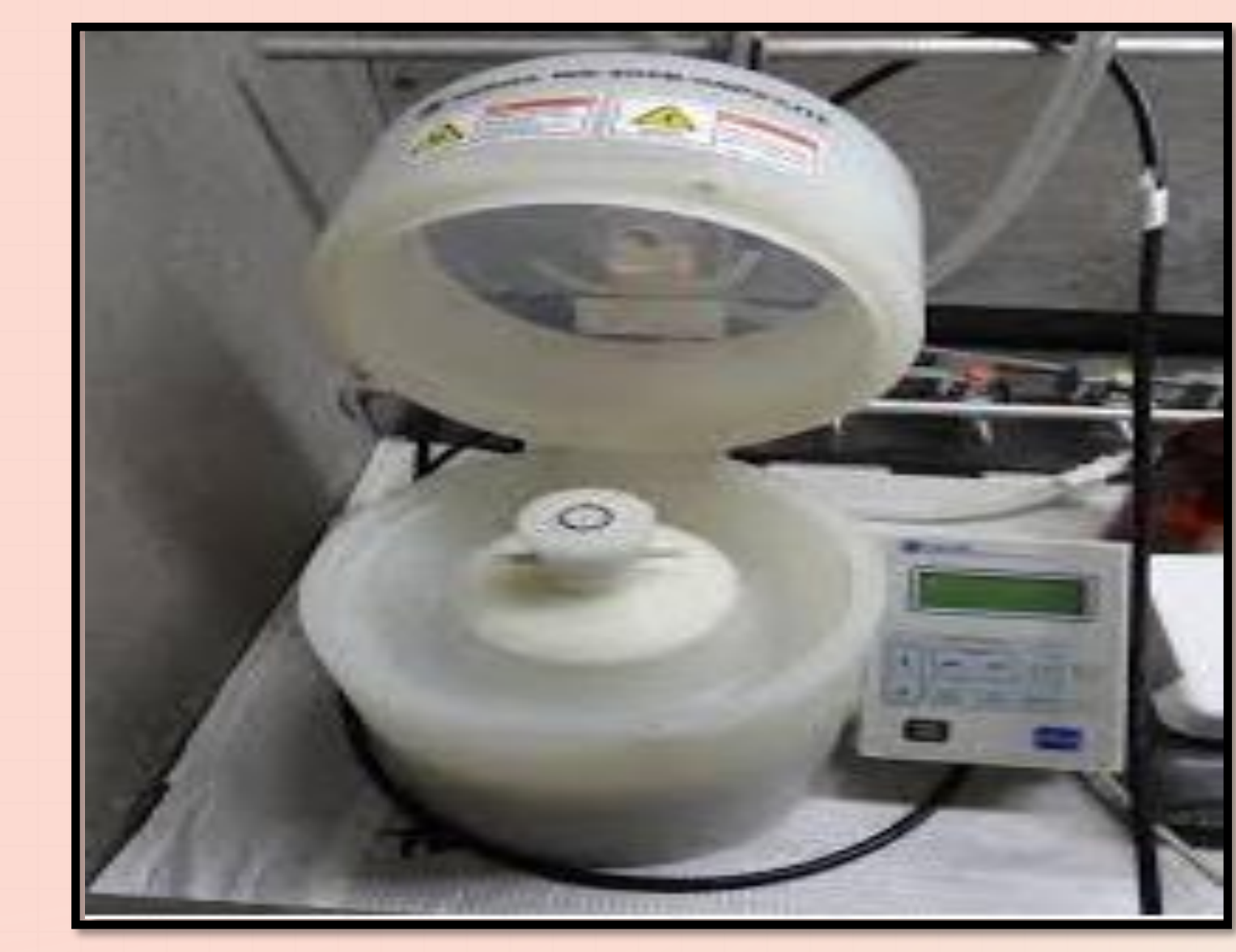

Figure 4: Spin Coating machine.

\section{Results \& Discussion}

\section{AFM and Contact Angle Analysis}

The Surface analysis of PVDF: $\mathrm{BaTiO}_{3}$ composite films done by AFM analysis. PVDF: $\mathrm{BaTiO}_{3}(2.5 \mathrm{wt} \%-0.5 \mathrm{wt} \%)$ composite films exposed to UV/Ozone treatment from $0 \mathrm{~min}$ to $10 \mathrm{~min}$. By applying UV/Ozone light the surface roughness of the film decreases as expected. However, the contact angle measurement shows that as we increase the exposing time for UV/Ozone treatment the nanocomposite film becomes more hydrophilic.

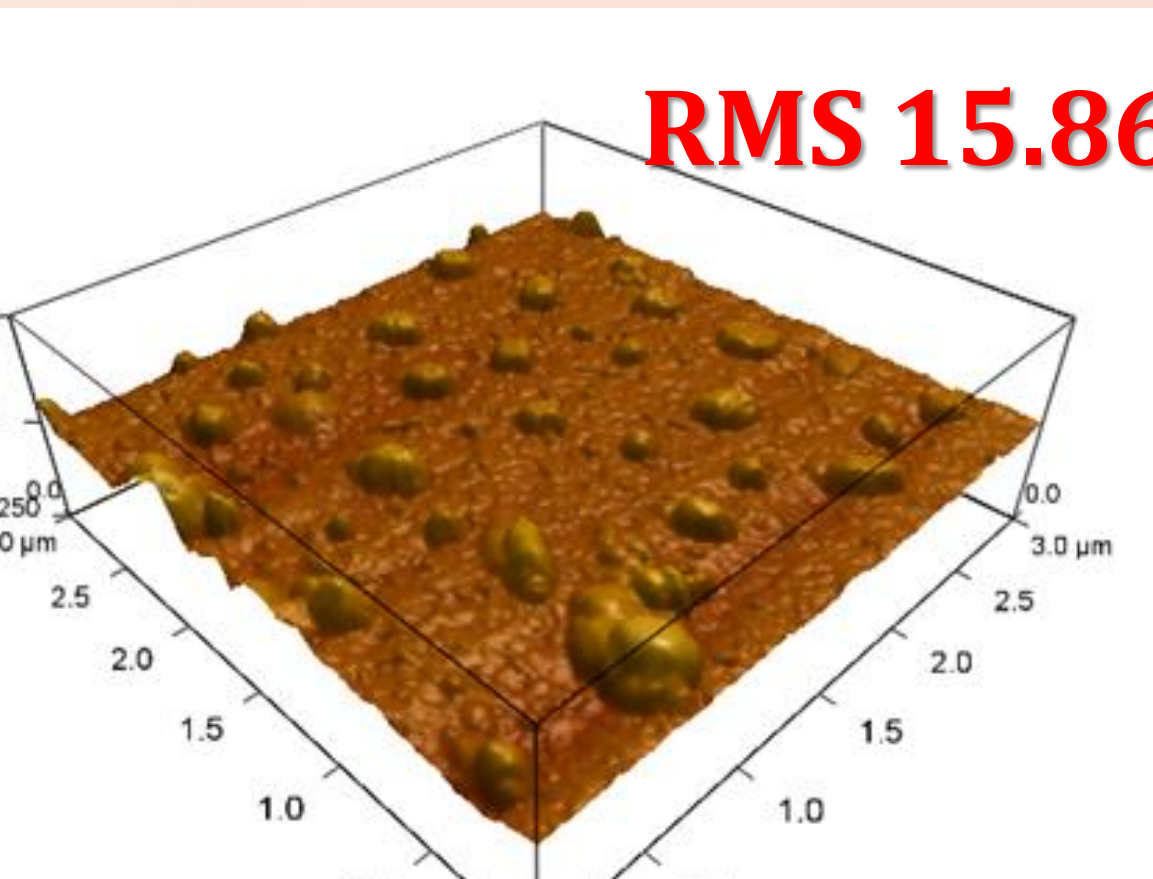

0 min UV

\section{(1)}

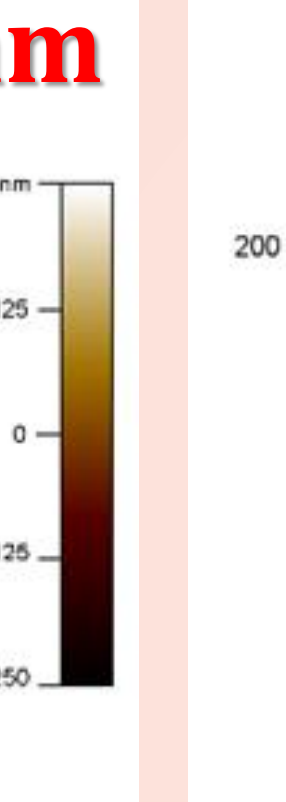

5 min UV

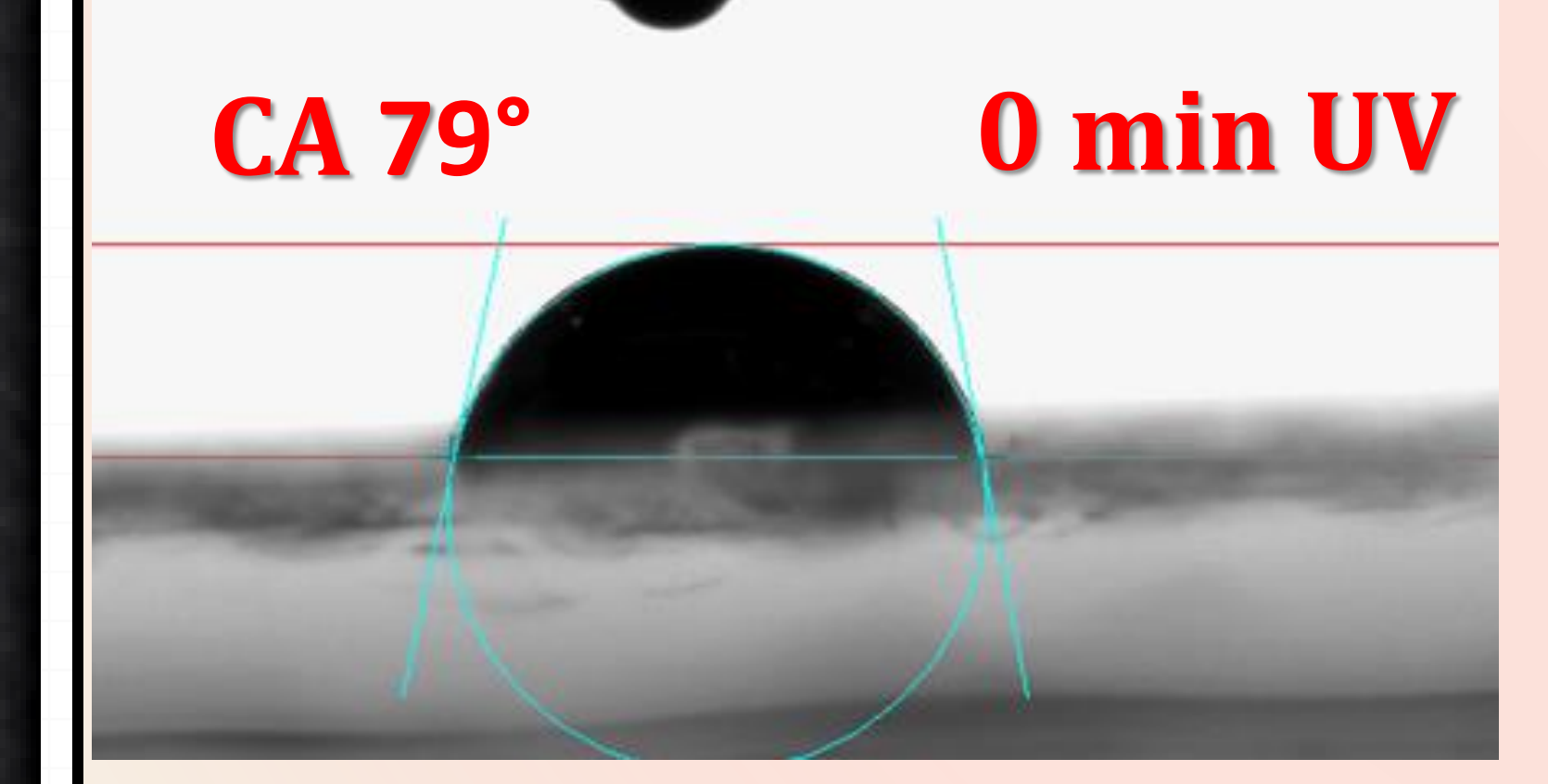

PVDF:BaTIO 3 ( 0.5 wt\%)
PVDF:BaTIO 3 ( 0.5 wt $\%)$

RMS 3.406nm

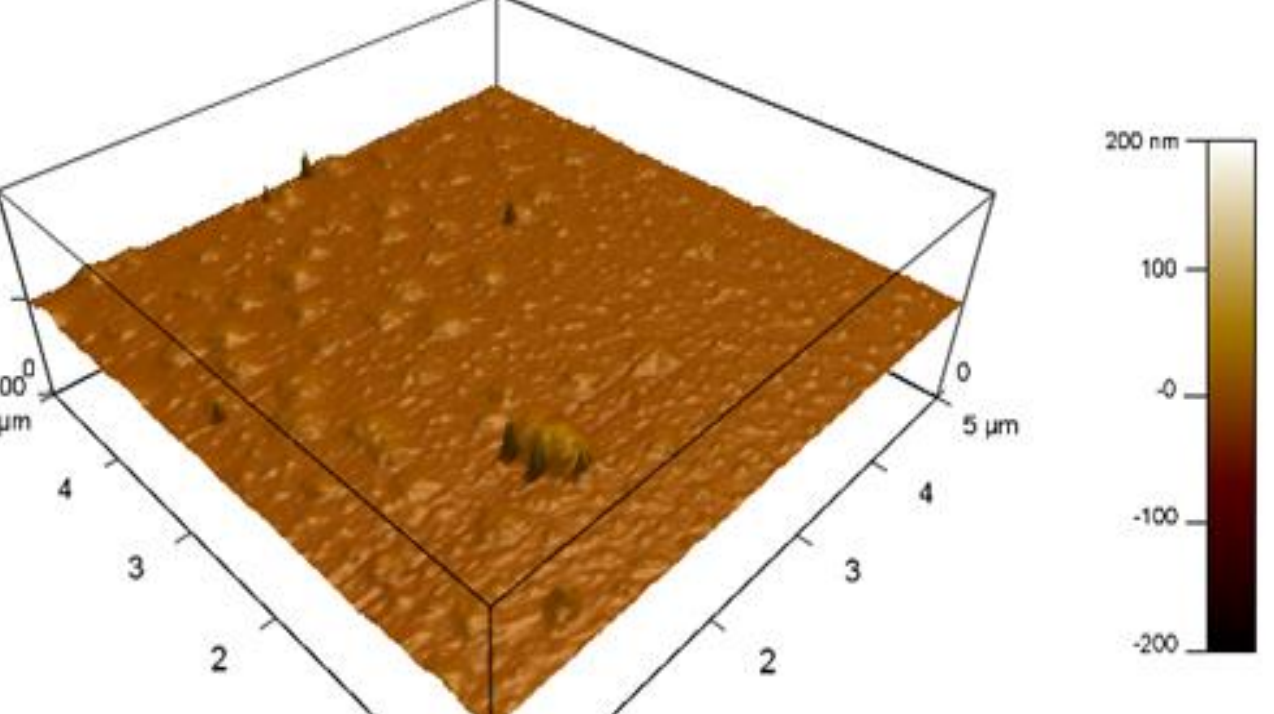

CA $50.8^{\circ}$

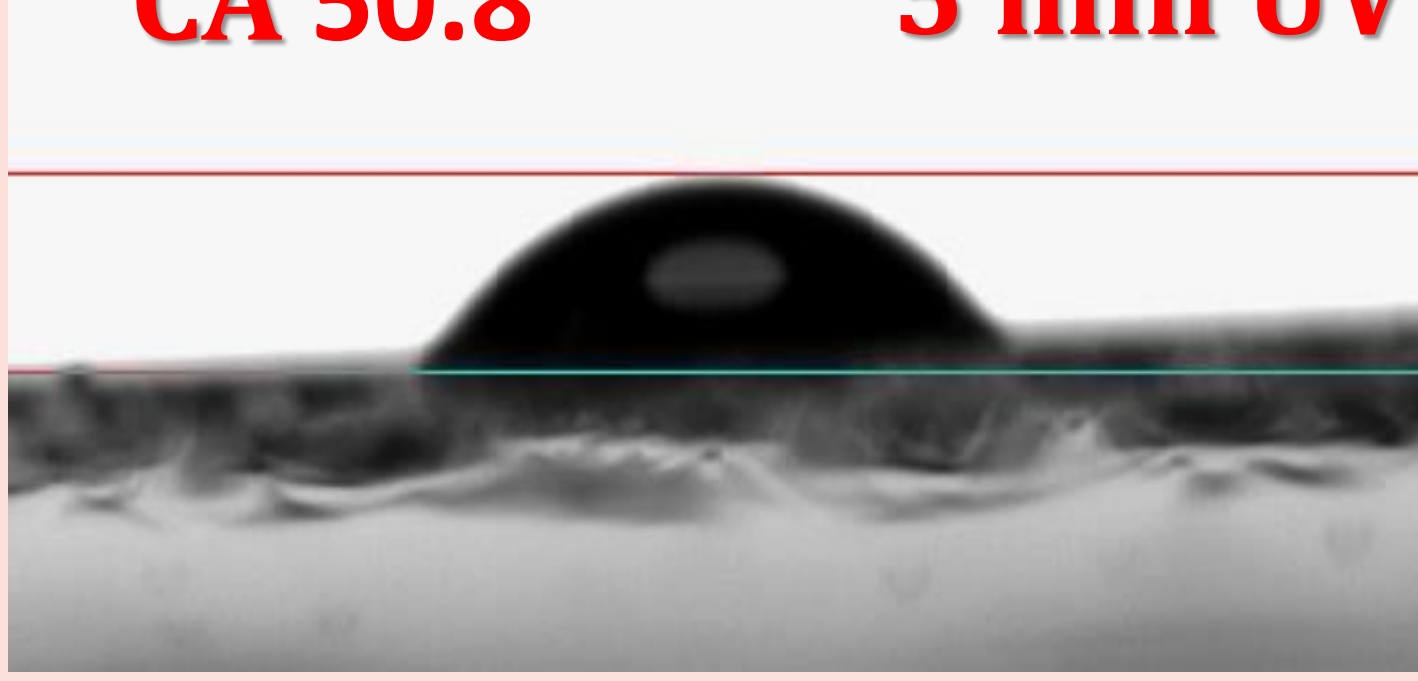

PVDF:BaTIO 3 ( 0.5 wt\%)
PVDF:BaTIO 3 ( 0.5 wt\%)

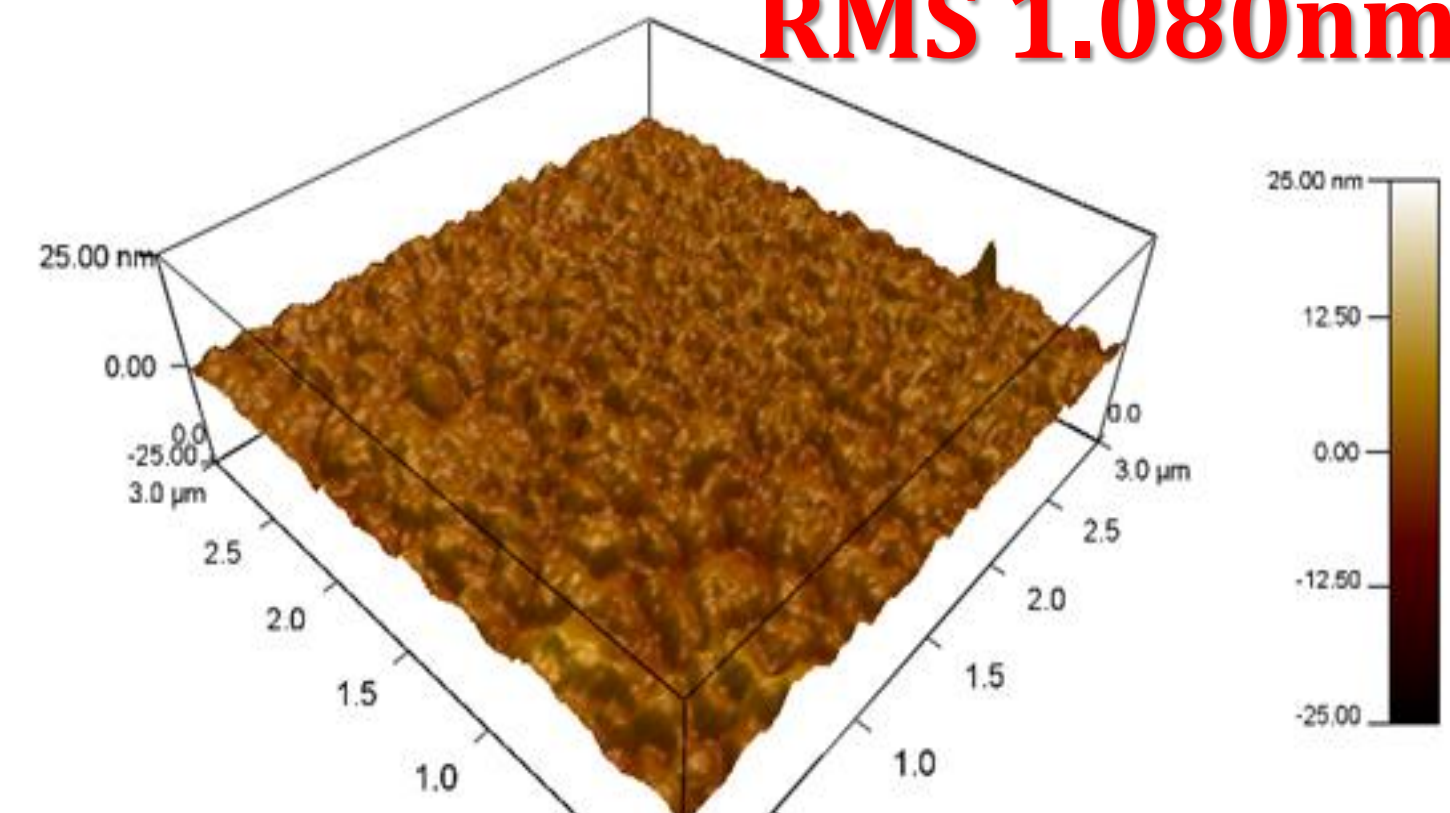

10 min UV

CA $34.35^{\circ}$

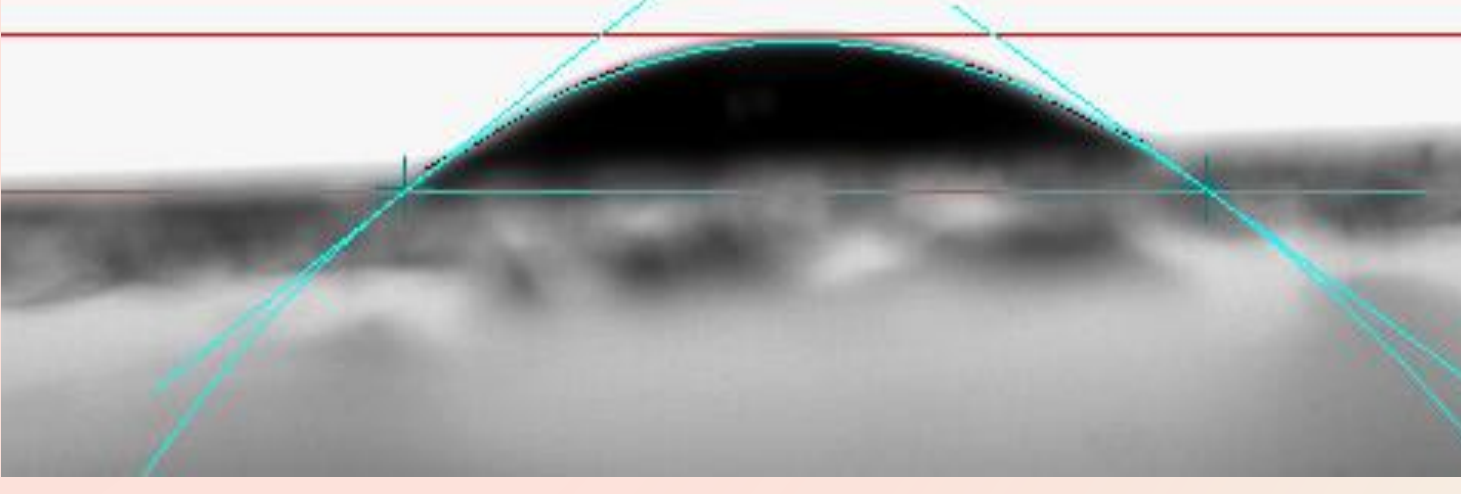

PVDF:BaTIO 3 ( $0.5 \mathrm{wt} \%$ )

Figure5: AFM analysis and contact angle measurement of $\mathrm{PVDF}_{\mathrm{BaTiO}}$ composite film exposing to UV/Ozone treatment for 0 min to 10 min.

\section{TGA and Electrical Response}

Thermal stability analysis of PVDF and PVDF: $\mathrm{BaTiO}_{3}$ composite done or

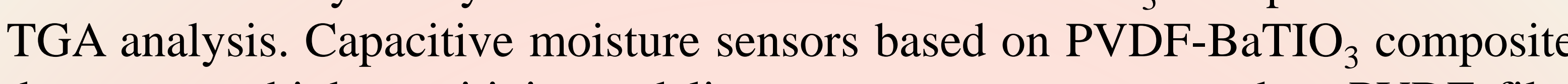
demonstrate high sensitivity and linear response as compared to PVDF film alone.
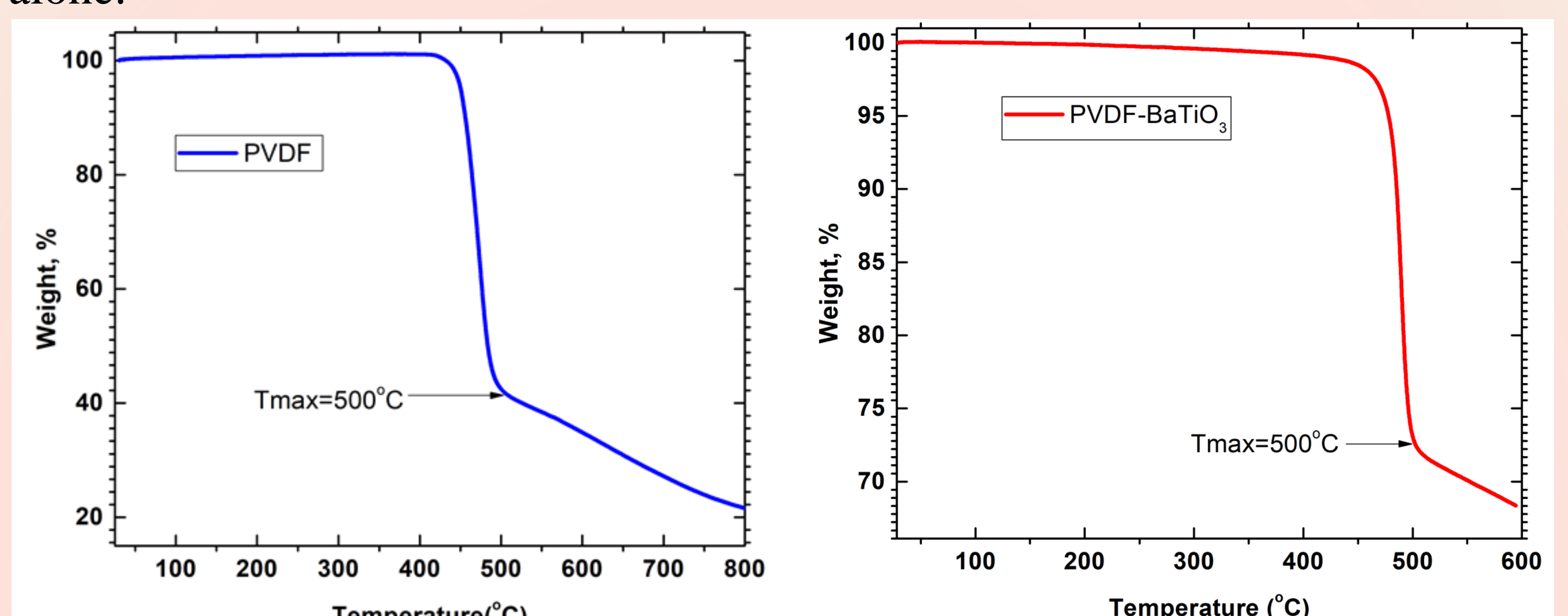

Figure6: TGA analysis of PVDF and PVDF-BaTiO 3 composite film
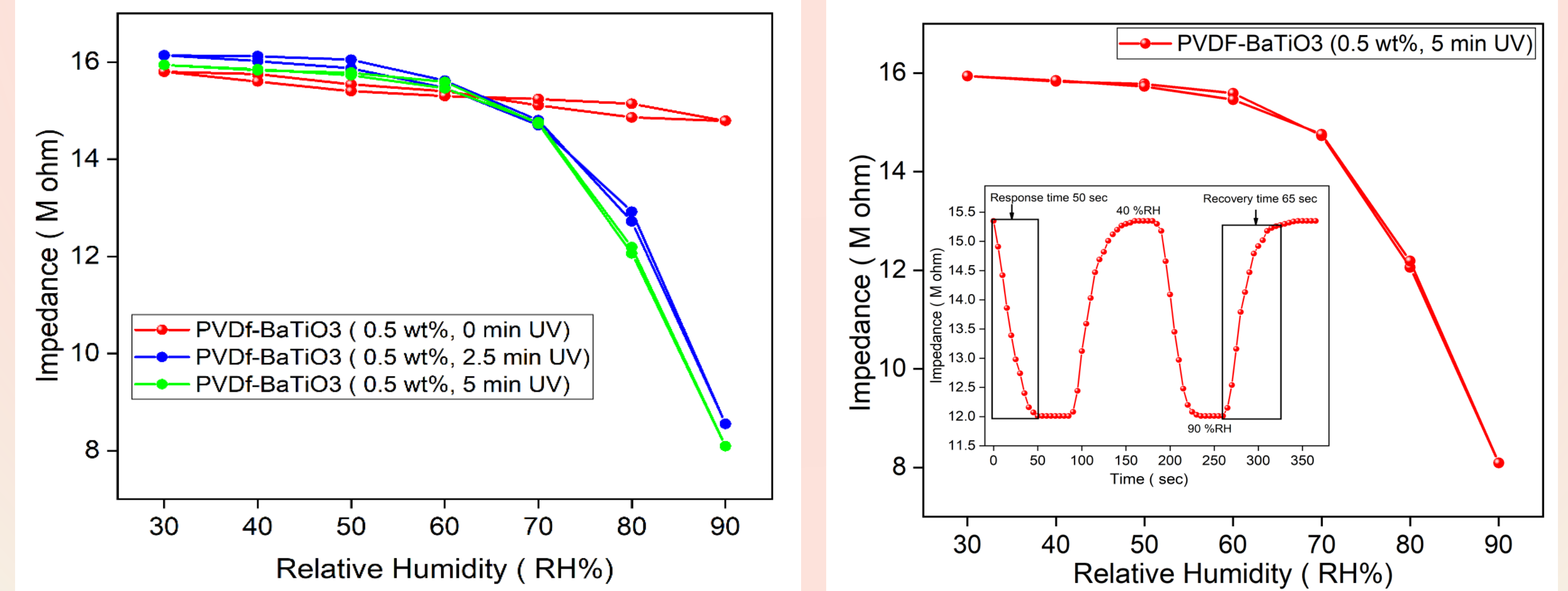

Figure7: Impedance vs Relative humidity level.

\section{Co}

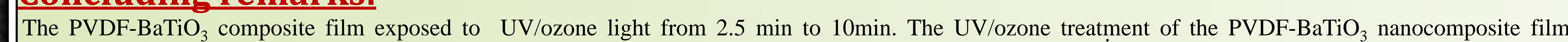
improves the sensing film's hydrophilicity. The TGA analysis reveals that PVDF-BaTIO ${ }_{3}$ composite are more stable as compared to PVDF film alone. The PVDF $\mathrm{BaTiO}_{3}(0.5 \mathrm{wt} \%)$ impedance sensor with $5 \mathrm{~min}$ UV/ozone treatment shows higher sensitivity and small hysteresis $(\sim 1.65 \%)$ over the whole investigated RH range. The response and recovery times of the fabricated $\mathrm{PVDF}-\mathrm{BaTiO}_{3}$ Impedance humidity sensor are calculated to be $50 \mathrm{~s}$ and $65 \mathrm{~s}$, respectively.

\section{Acknowledgement:}

The author are thankful to Centre of Advanced Materials (CAM), for proving the laboratory support. 